\title{
Design and Pitch Angle Optimisation of Horizontal Axis Hydrokinetic Turbine with Constant Tip Speed Ratio
}

\author{
Suyash Nigama, Shubham Bansal, Tanmay Nema, Vansh Sharma and Raj Kumar Singh \\ Department of Mechanical, Automotive and Production Engineering, Delhi Technological University, Delhi, India
}

\begin{abstract}
Booming population and associated energy demands, looming threat of exhaustion of conventional sources of energy and the severe environmental repercussions of the same call for alternate sources of clean energy. Hydrokinetic turbine is one such developing technology which harnesses zero-head free flow of water and affects hydrological ecology minimally. This paper discusses the optimisation of Horizontal Axis Hydrokinetic Turbine (HAHkT) blade chord length and twist angle using blade element momentum (BEM) theory to achieve a constant optimal angle of attack (AoA), thus maximising the power output. To achieve this while maintaining robustness at the hub end and eliminate cavitation, two different hydrofoils (S832 and E817) are selected. S832 is simulated using ANSYS 14.0 at low $\left(0^{\circ}\right)$ and high $\left(15^{\circ}\right)$ angles of attack and compared against more widely used NACA 4412 to study flow separation characteristics. This is followed by calculating angles of relative flow, ratios of chord length and subsequently twist angles for each blade element using MATLAB simulations. A blade model is thus developed for visualisation using computer aided designing after obtaining optimal chord lengths and pitch angles.
\end{abstract}

\section{Introduction}

Today's world sees an unprecedented demand for clean and economic sources of energy. Globally, 1.6 billion do not have access to electricity. [1] This calls for a greater shift in focus towards the renewable sources of energy for an energy-secure future.

According to IEA report in 2014, hydropower constitutes about $16.2 \%$ of our total energy demands and thus presents a great alternative. [2] However there are several problems associated with the creation of dams and embankments on water bodies to create power, such as sedimentation in the water bodies, significant damage to the aquatic ecosystem and socio-political concerns over displacement of multitudes of people.

Hydrokinetic turbine is a technology which harnesses zero-head free flow of water and presents a low emission way to satisfy the increasing energy demand while minimally affecting the hydrological ecology. This makes these turbines a lucrative alternative in a developing country like India which has a high hydropower potential.

These hydrokinetic turbines are advantageous as compared to wind power because of more predictability of the medium of flow, higher level of energy extraction due to near surface placement, minimal infrastructural investment, reduced environmental hazards and lower noise problems.

The primary classification of these turbines is done on the basis of axis of rotation relative to the flow- horizontal and vertical hydrokinetic turbines. Vertical axis hydrokinetic turbines are subject to some inherent

\footnotetext{
a Corresponding author: suyashnigam@dtu.ac.in
}

disadvantages such as high starting torque requirements, lower power output at same flow velocity and higher vibrational losses. However Horizontal Axis Hydrokinetic Turbines (HAHkTs) improve upon these problems.

\section{Literature review}

Hydrokinetic turbines have seen a lot of research work over the past 2 decades. Ducted horizontal hydrokinetic turbines such as two-bladed SeaGen project turbines in the UK manufactured by Marine Current Turbines Limited are axial flow rotors whose mechanism is similar to that of a wind turbine with a capacity of $300 \mathrm{~kW}$ 1.2MW. [3-5] Three-bladed Hammerfest Strom turbine (Norway) incorporates arrays of multi rotor underwater turbines whose energy is transported using subsea cables running on a maximum capacity of $300 \mathrm{~kW}$. Verdant Power has developed two projects- Roosevelt Island Tidal Project (RITE, New York East River, US) [6-8] and Cornwall Ontario River Energy Project (CORE, St. Lawrence River, Canada) [9] projects. It installs turbines which self-rotate from prevailing currents with optimally designed blades. These operate at $35 \mathrm{~kW}-1 \mathrm{MW}$ capacity. Un-ducted hydrokinetic turbines comprise those such as multi-bladed Lunar Energy Rotate Tidal Turbine, housed in a converging-diverging duct so as to create a venturi action, and multi-bladed Underwater Electric Kite (UEK) Corp. [10] who now operate a fully functional plant at Eagle, Alaska. 
From studying the functional projects, potency and viability of these hydrokinetic turbines can be established. Since HAHkT offer various advantages over the vertical ones, the design optimisation of the same will be the primary objective of this research.

\subsection{Selection of hydrofoil geometry}

A hydrofoil is a two dimensional surface which operates in water, producing lift force. The following parameters were found to be desirable:

- Glide ratio: This is a measure of the force of lift vs drag. It is important because lift is the primary source of power generation in horizontal axis turbines.

- Stall angle: The foil must produce lift until a high AoA as the velocity of flow varies greatly. Foils with high stall angles must be used towards the tip of the rotor, where the linear velocity is maximum.

- Leading edge area: The leading edge surface area must be small so as to reduce skin friction drag.

- Aft-loading: The trailing edge geometry must permit high values of aft-loading to counter cavitation.

\subsection{Series of hydrofoils studied}

Many organisations have worked in developing novel foils and studying the viability of already popular foils which are employed for wind turbines and commercial aeronautics.

a) NACA 4 series profiles: The NACA 4412 foil was used extensively for horizontal axis wind turbines (HAWT) purposes owing to large glide ratio values.

b) NREL $\mathrm{S}$ Series: National Renewable Energy Laboratory designed several geometries specifically for HAWT. Although they produce lesser coefficient of power than the NACA 4 series, they can be designed to operate at various tip speed ratios. [11]

c) NACA 5 Series: They have a high value of maximum coefficient of lift and can be used at operation near stall angle and off design conditions.

d) Eppler foils: Eppler E817 foil produces close to zero cavitation till 700 pounds per square inch aft loading. [12] This is achieved by using under cambered trailing edges.

e) Delft University Foils: These foils have a specific Scurve in trailing edge [13] to increase permissible aftloading and a small upper surface area to decrease skin friction.

Several parameters were discussed upon for the optimisation process, namely solidity, chord length, pitch angle, hub design, number of blades, etc. Among these the optimisation of chord length and pitch angle was chosen as the objective of our work because the angle of relative velocity changes at every blade element. To maintain a high coefficient of lift, an optimal AoA is desirable and hence the pitch angles at every blade element have to be optimised accordingly.

\section{Methodology}

The methodology selected for developing a computational model of the HAHkT involves the selection of hydrofoil using $\mathrm{k}-\omega$ turbulence model using Ansys Fluent, optimisation of pitch angle and chord length using MATLAB simulations and development of the optimised blade profile using computer-aided modelling for visual representation through Solidworks.

\subsection{Procedure for ANSYS simulation}

We decided to do a computational analysis of NACA 4412 foil and the NREL S832.

ANSYS Fluent was deployed to index the performance of hydrofoil under various spatial arrangements. For the 2 dimensional computational analysis a standard foil geometry was modeled using ANSYS design modeler and a C-mesh was constructed by employing ANSYS mesh module.

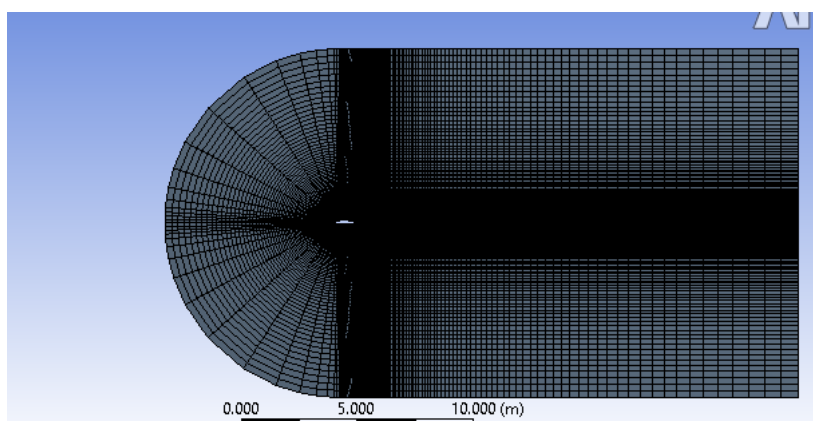

Figure 1. C-Mesh of control volume.

The number of nodes are in the 20,000 range with detailed meshing near the foil boundary so as to accurately capture the physics of boundary-layer flow. Mapped meshing operation was selected and the resultant mesh is displayed in Figure 1.

Simulation parameters:-

Inlet: Velocity inlet

Outlet: Pressure Outlet

Fluid density: $999.7 \mathrm{~kg} / \mathrm{m}^{3}$

Inlet velocity $(\mathrm{U}): 2 \mathrm{~m} / \mathrm{s}$

Number of iterations: 500

Turbulence model: The k- $\mathcal{\omega}$ [14] model was chosen by the virtue of its proven robustness in accurately predicting turbulent flow without high computational requirements.

It's a 2 equation model where ' $k$ ' stands for turbulent kinetic energy and ' $\omega$ ' the specific dissipation rate. ' $\mathrm{k}$ ' and ' $\boldsymbol{\omega}$ ' are computed by empirical relations [15]:

$$
\begin{gathered}
k=\frac{3}{2}(U * I)^{2} \\
\omega=C \mu^{\frac{-1}{4}} * \frac{\sqrt{k}}{l}
\end{gathered}
$$

where ' $l$ ' is 0.02 meters and denotes average Prandtlmixing length typically $10 \%$ of chord length of $0.2 \mathrm{~m}$. 'I' 
is the ratio of fluctuation component of velocity to the root mean square velocity of the flow, called turbulence intensity. The value of ' $\mathrm{I}$ ' for a rotating turbomachinery component is around $10 \%$. ' $\mu$ ' is the viscosity of flow.

\subsubsection{Simulation results}

The computation was carried out for NREL S832 and NACA 4412 at 0 degree AoA and a high AoA of 15 degrees to gain insight in flow phenomenon at varying conditions.

At higher AoA the flow separates in case of NACA 4412 while the flow is largely attached in the case of NREL S832. This implies S832 is more robust against varying angular positions.

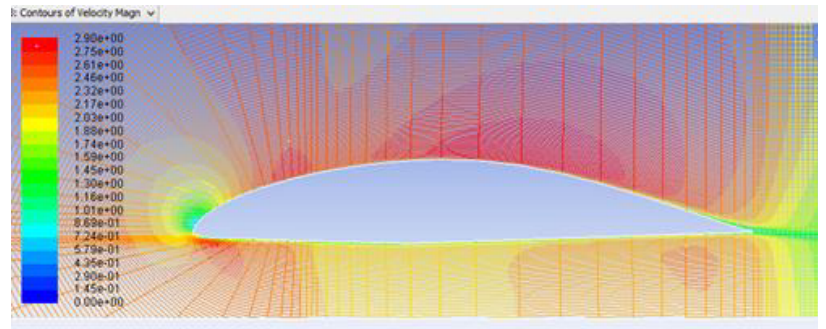

Figure 2. S832 at 0 degree AoA.

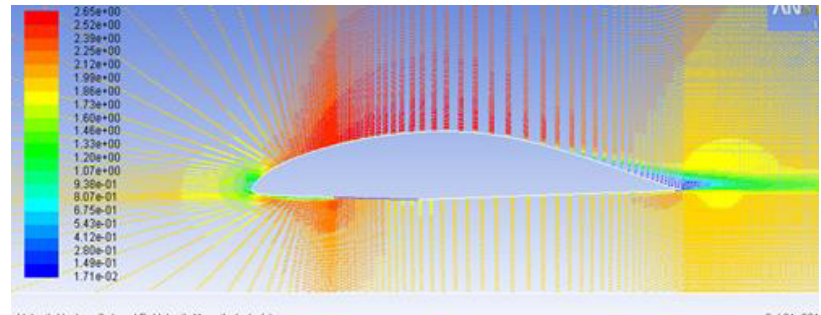

Figure 3. S832 at 15 degree AoA.

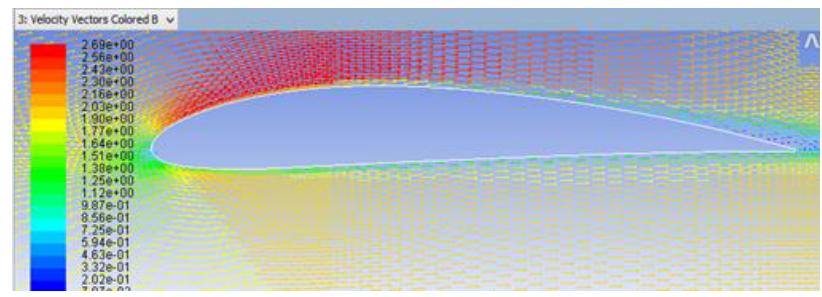

Figure 4. NACA 4412 at 0 degree AoA.

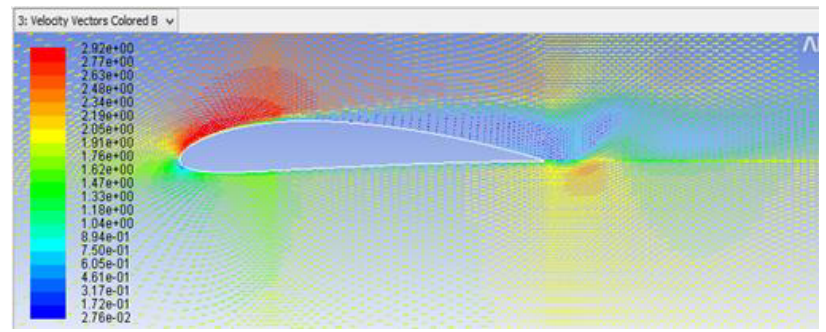

Figure 5. NACA 4412 at 15 degree AoA.

\subsection{Optimisation of blade chord length and pitch angle}

Two of the most important parameters in deciding the hydrofoil profile and orientation for the turbine blade so as to achieve maximum power output are: ratio of the area occupied by blade with respect to the total area covered by the blade (solidity) and the angle of relative velocity.

Simulation of blade profile data to optimise the chord length and the element twist angle along the length of the blade are done to achieve maximum power output. The variable pitch is important so as to operate at fixed optimal AoA for the respective hydrofoil geometry.

The following assumptions were made for calculations:

- The blade is considered to be a combination of discrete elements of equal length instead of a long single unit.

- The tip speed ratio (TSR) at each element varies linearly along the length of the blade.

- The induced velocity at each element is determined by performing the momentum balance for an annular control volume containing the blade element.

- Tip losses and hub losses and vortices are ignored.

For a specific AoA lift coefficient must be maximum, drag should be minimum while neither flow separation nor cavitation should occur. Optimal pitch angle enables the system to operate at higher relative water velocities. Hydrokinetic turbines are subjected to high thrust and torsional loads due to high density of water which causes high bending moment at the blade root. So, thicker blade sections are preferred near the hub.

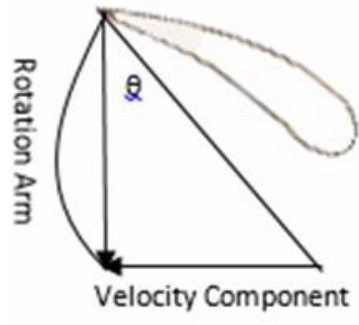

Fine Pitch

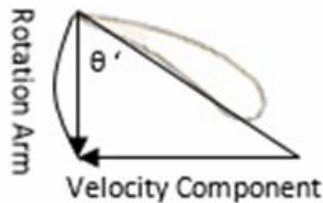

Course Pitch
Figure 6. Variation of Relative Velocity Angle with pitch.

At a given water speed, the speed of different blade sections differ depending upon the distance of the section from the hub i.e the rotation arm. We observe that this results in a very low AoA for the sections closer to hub. This needs to be rectified. This is achieved by going for a coarse pitch for the closer section and a fine pitch for sections as we move away from hub.

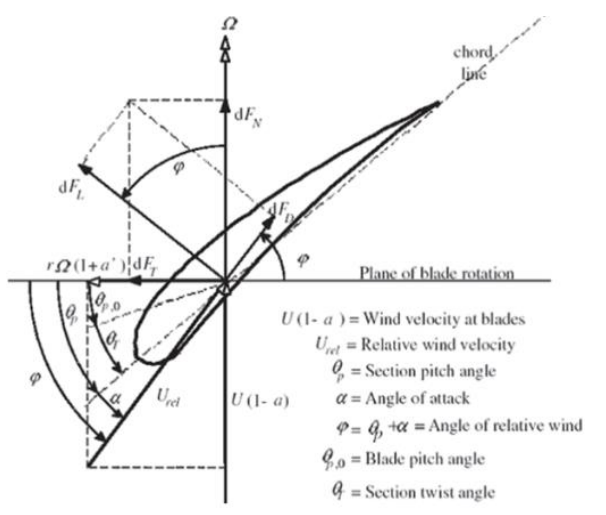

Figure 7. Blade Element Momentum Theory Parameters. 


\subsubsection{MATLAB simulation}

The following parameter values are used:

Number of blades $=\mathrm{B}=3$

Tip Speed Ratio $=\mathrm{TSR}=3$

Rated Water Speed $(\mathrm{m} / \mathrm{s})=2$

Estimated efficiency of system $=0.45$

Rotor diameter $(\mathrm{m})=(\mathrm{d})=2.2$

Number of blade elements $=($ ne $)=10$

AoA for max $\mathrm{L} / \mathrm{D}$ ratio for $\mathrm{S} 832(\alpha 1)=9.75$

AoA for max L/D ratio for E817 $(\alpha 2)=7.5$

Lift coefficient for $\mathrm{S} 832(\mathrm{Cl} 1)=1.1207$

Lift coefficient for E817 $(\mathrm{Cl} 2)=0.9083$

Drag coefficient for $\mathrm{S} 832(\mathrm{Cd} 1)=0.0622$

Drag coefficient for E817 $(\mathrm{Cd} 2)=0.04476$

An element data matrix is prepared in MATLAB after successive iterations of the calculations on initial data. The hydrofoils E817 and S832 are used in the ratio of length as 1:3.

Length of each element $=(\mathrm{L})=(\mathrm{d} / 2) /$ ne

Distance from hub $=(\mathrm{R})=\mathrm{L} / 2+(\mathrm{i}-1) * \mathrm{~L}$

Tip Speed Ratio $=(\mathrm{TSR})=\Omega \mathrm{R} / \mathrm{V}$

Local Tip Speed Ratio $=(\mathrm{LSR})=\mathrm{TSR} *(\mathrm{R} /(\mathrm{d} / 2))$

Angle of relative velocity $=\varphi=(2 / 3) * \tan ^{-1}(1 /$ LSR $)$

Chord Length for $\mathrm{S} 832=\left(8^{*} \pi^{*} \mathrm{~L}^{*}(1-\varphi) /\left(\mathrm{B}^{*} \mathrm{Cl} 1\right)\right.$

Chord Length for E817 $=\left(8^{*} \pi^{*} \mathrm{~L} *(1-\varphi) /\left(\mathrm{B}^{*} \mathrm{Cl} 2\right)\right.$

Pitch angle (in radians) $=\theta=(\varphi-\alpha)$

Solidity Ratio $=\sigma=\mathrm{B} * \mathrm{c} /(2 \pi \mathrm{r})$

\subsubsection{Results and inference}

The twist angle/pitch angle output obtained from the optimisation code is mentioned in Table 1. This is obtained by using the following relation: $\theta=(\varphi-\alpha)$

The first blade element is considered at the hub end and the successive blades are positioned radially outwards.

Table 1: Element Data Parameters from MATLAB Code.

\begin{tabular}{|c|c|c|c|c|c|}
\hline $\begin{array}{c}\text { Elem } \\
\text { ent } \\
\text { No. }\end{array}$ & $\begin{array}{c}\text { Radial } \\
\text { Distance } \\
\text { Ratio (R/ } \\
(\mathbf{d} / \mathbf{2})\end{array}$ & LSR & $\begin{array}{c}\text { Angle of } \\
\text { Relative } \\
\text { Velocity } \\
\mathbf{(}^{\mathbf{(}} \mathbf{n}\end{array}$ & $\begin{array}{c}\text { Ratio of } \\
\text { Chord } \\
\text { with } \\
\text { radial } \\
\text { distance }\end{array}$ & $\begin{array}{c}\text { Pitch } \\
\text { Angle } \\
(\mathbf{0})\end{array}$ \\
\hline 1 & 0.05 & 0.15 & 54.313 & 0.192 & 46.813 \\
\hline 2 & 0.15 & 0.45 & 43.848 & 0.386 & 36.348 \\
\hline 3 & 0.25 & 0.75 & 35.420 & 0.346 & 25.670 \\
\hline 4 & 0.35 & 1.05 & 29.069 & 0.330 & 19.319 \\
\hline 5 & 0.45 & 1.35 & 24.353 & 0.299 & 14.603 \\
\hline 6 & 0.55 & 1.65 & 20.812 & 0.268 & 11.062 \\
\hline 7 & 0.65 & 1.95 & 18.100 & 0.240 & 8.350 \\
\hline 8 & 0.75 & 2.25 & 15.975 & 0.217 & 6.225 \\
\hline 9 & 0.85 & 2.55 & 14.275 & 0.196 & 4.525 \\
\hline 10 & 0.95 & 2.85 & 12.890 & 0.179 & 3.140 \\
\hline
\end{tabular}

For blade elements upto one-fourth of the length of the blade, the AoA is chosen for S832 blade profile i.e. $\alpha 1$ and for the remaining three-fourth length, that of E817, i.e. $\alpha 2$.

a) Chord Length vs Ratio of Radial Distance: Figure 8 shows the graph. The maxima of the chord length is at a value of ratio of radial distance close to 0.15 , i.e. between the first and second element. Beyond that, it gradually decreases, narrowing upto the tip. This is in line with the aim to model blades with thicker sections towards the hub so as to bear the high bending moment at the blade root.

b) Angle $\varphi$ vs Ratio of Radial Distance: Figure 9 shows the graph. It shows a continuous decreasing trend of angle of relative velocity with respect to the radial distance. Decreasing angle of relative velocity result in a lesser lift force and thus a lower TSR towards the root of the blade i.e. the inner elements. Higher relative velocity angles also indicate a higher value of twist angles towards the root of the blade because of the constant AoA for a given blade profile.

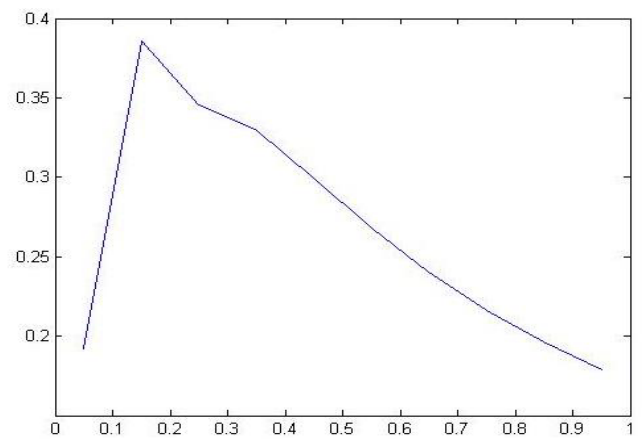

Figure 8. Graphical representation of Chord Length vs Ratio of Radial Distance.

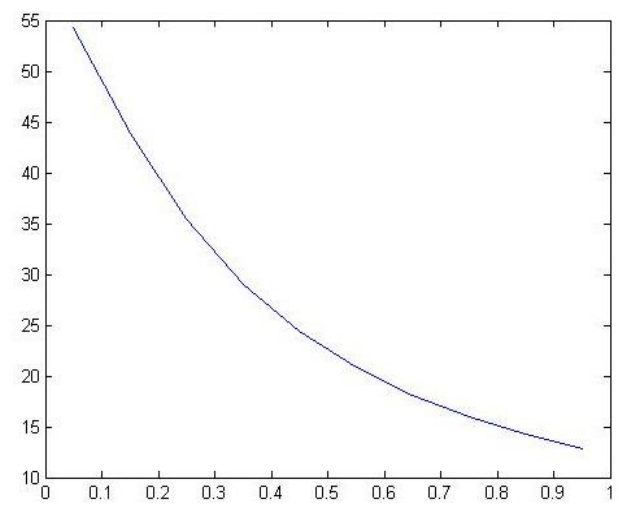

Figure 9. Graphical representation of Angle $\varphi$ vs Ratio of Radial Distance.

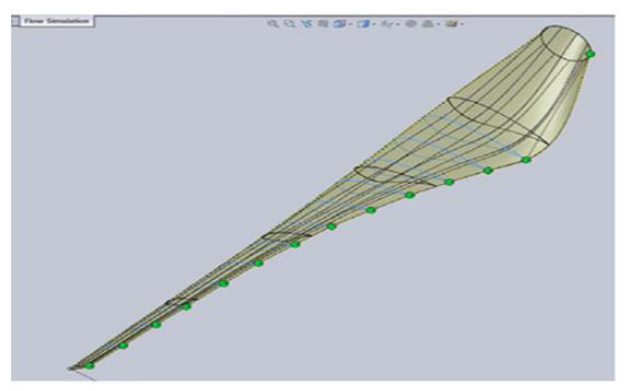

Figure 10. Optimised blade model. 


\subsection{Computer aided design of blade model}

The different profiles are generated by the obtained phase angle and chord length values. Higher the number of blade elements, more accurate blade geometry results will be obtained.

The Fig. 10 depicts the development stages of the blade model.

The primary function of the hub body is to transfer the load from the blades to the low speed shaft. The hub diameter of the turbine is kept $40 \%$ of the blade length. The hub design is in accordance with the work of $\mathrm{J}$. Cotrell. [17]

\section{Conclusion}

The HAHkT blade is formed of two hydrofoil geometries which are twisted about an axis so as to maintain the optimum AoA. The blade uses a combination of E817 and S832 foils. The distribution of the profiles is as follows: E817 constitutes of $25 \%$ of the total blade length on the hub end to reduce stresses and avoid cavitation, and the remaining $75 \%$ is $\mathrm{S} 832$ for no-flow separation even at higher AoA. The hydrofoils are arranged along a common axis to form a blade model which consists of three uniformly distributed blades as shown in Fig. 11.

This HAHkT blade model improves upon the structural stability and power output characteristics of traditional single hydrofoil constant twist angle profiles and thus holds promise as an efficient model.

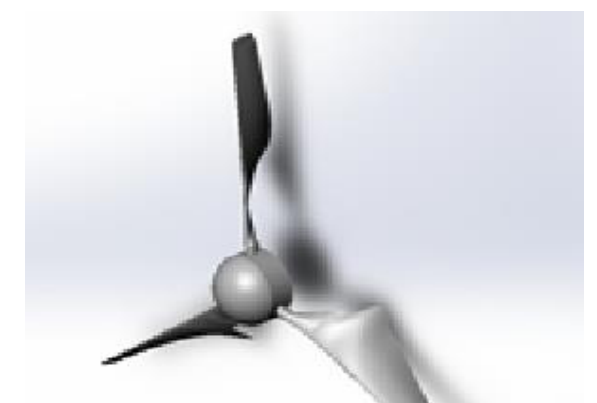

Figure 11. CAD prototype of turbine.

\section{References}

1. BP: Statistical Review of World Energy, Workbook (xlsx), London, (2013)

2. http://www.iea.org/publications/freepublications/

3. SeaGen Environmental Monitoring Programme Final Report, as available on http://seageneration.co.uk/files/SeaGenEnvironmental-Monitoring-Programme-FinalReport.pdf, accessed on October 24, 2015

4. C.A. Douglas, G.P. Harrison, J.P. Chick, Life cycle assessment of the Seagen marine current turbine. Proceedings of the Institution of Mechanical Engineers

5. A. Røkke, R. Nilssen, Marine Current Turbines and Generator preference. A technology review, International Conference on Renewable Energies and Power Quality (ICREPQ'13) Bilbao (Spain)(2013)

6. J. Colby. Multi-scale Hydrodynamic analysis of kinetic hydropower arrays. NortekUSA Technical Symposium (2011)

7. Verdant Power, Inc, Final Report - GO18168 Improved Structure and Fabrication of Large, HighPower KHPS Rotors, Award No. DE-FG3608GO18168

8. D. Sale, J. Jonkman, W. Musial, A Hydrodynamic Optimization Method and Design Code for StallRegulated Hydrokinetic Turbine Rotors (2009)

9. http://www.powertechnology.com/projects/cornwall-ontario-riverenergy-project/, as accessed on October 27, 2015.

10. P. Vauthier. The underwater electric kite. East river deployment, UEK Corporation.

11. http://www.nrel.gov/docs/legosti/old/7109.pdf

12. http://www.foils.org/hysecdes.pdf

13. https://gcep.stanford.edu/pdfs/energy_workshops_04 04/wind van rooij.pdf

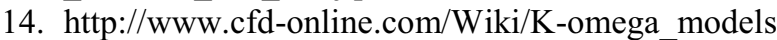

15. http://www.cfdonline.com/W/index.php?title=Turbulence_freestream boundary conditions\&oldid $=2269 \overline{3}$

16. J. Cotrell, The Mechanical Design, Analysis, and Testing of a Two-Bladed Wind Turbine Hub (1995) 